\title{
Fertilization in a sea urchin is not only a water column process: effects of water flow on fertilization near a spawing female
}

\author{
Florence I. M. Thomas ${ }^{1, *}$, Louise T. Kregting ${ }^{1,2}$, Brian D. Badgley ${ }^{3,4}$, \\ Megan J. Donahue ${ }^{1}$, Philip O. Yund ${ }^{2,5}$ \\ ${ }^{1}$ Hawai'i Institute of Marine Biology, University of Hawai'i, PO Box 1346, Kane'ohe, Hawai'i 96744, USA
${ }^{2}$ Marine Science Center, University of New England, 11 Hills Beach Rd, Biddeford, Maine 04005, USA \\ ${ }^{3}$ Department of Biology, University of South Florida, 4202 E. Fowler Ave, Tampa, Florida 33620, USA \\ ${ }^{4}$ Present address: Crop and Soil Environmental Sciences, Virginia Tech, Blacksburg, Virginia 24961, USA \\ ${ }^{5}$ Present address: The Downeast Institute, PO Box 83, Beals, Maine 04611, USA
}

\begin{abstract}
Fertilization efficiency in free-spawning invertebrates in the marine environment depends on the complex interaction between biological and physical factors. Experimental evidence indicates that in some taxa, a considerable amount of fertilization may take place on the substrate and within flow structures in close proximity to a spawning female. Gametes can be retained on a spawning animal, resulting in their slow release over relatively long periods of time, and retained eggs can be fertilized before they are released into the water column. Hydrodynamic conditions are likely to influence both the retention of gametes and their subsequent mixing in the water column as well as the relative importance of fertilization in the water column and in other locations near spawning animals. Here, fertilization in the broadcast-spawning sea urchin Strongylocentrotus droebachiensis was explored over a range of flow velocities $\left(\bar{u}=2\right.$ to $\left.15 \mathrm{~cm} \mathrm{~s}^{-1}\right)$ to determine the effect of velocity on fertilization and the relative contribution of different locations (aboral surface of the female, water column, wake, and the substrate behind the female) to overall fertilization. As velocity increased, the percentage of eggs fertilized declined in all locations. At all velocities, more eggs were fertilized on the aboral surface than in the water column. Further, as velocity increased, the relative contribution of the aboral surface to overall fertilization increased. These results highlight the importance of considering the interaction of hydrodynamics, organism morphology, and gamete properties in studies of fertilization in broadcast-spawning invertebrates.
\end{abstract}

KEY WORDS: Broadcast spawning $\cdot$ Gamete properties $\cdot$ Hydrodynamics $\cdot$ Free spawning

\section{INTRODUCTION}

Fertilization in broadcast-spawning marine invertebrates occurs within the context of complex interactions between hydrodynamic conditions and gamete properties. In the simplest view, gametes are released from a spawning animal and mix in the water column where fertilization occurs. In this scenario, hydrodynamic conditions and gamete properties that influence rates of mixing in the water column control the efficiency of fertilization. This perspective has provided a detailed view of controls on fertilization and has greatly expanded our understanding of how hydrodynamics and gamete properties influence fertilization (Denny et al. 1992, 2002, Mead \& Denny 1995, Levitan 2002, 2004, 2005, 2008, Crimaldi \& Browning 2004, Levitan \& Ferrell 2006, Gaylord 2008, Crimaldi 2012). However, fertilization in broadcast-spawning inverte- 
brates is influenced by a wider suite of processes than just those that control mixing of gametes in the water column. Spawn is viscous (Thomas 1994a) and can be retained on animals, where fertilization may occur as eggs are released (Svane \& Havenhand 1993, Marshall 2002,Yund \& Meidel 2003), or within clouds or strings of sperm formed on the surface of a spawning male. Experimental evidence indicates that in some taxa that project above the substrate, fertilization can take place on the surface of spawning animals and within the turbulent wake formed behind these animals; gametes may also sink to the substrate where fertilization occurs. Therefore, fertilization may better be viewed as a complex process that includes mixing of gametes in the water column as only one of the major component processes.

Hydrodynamic regime is also likely to play a complex role in fertilization beyond that understood to control rates of mixing in the water column. Turbulence and velocity of water affects the retention of gametes on the surface of an animal (Thomas 1994a; also see Fredsoe \& Deigaard 1992, Gyr \& Kinzelbach 2003 for effects of hydrodynamics on general particle transport) and the size and shape of the wake formed behind the animal. Spawning occurs within the benthic boundary layer, and the movement of gametes into free-stream flows may be limited (Jumars et al. 2001), although some organisms may adopt behaviors that minimize boundary layer effects (Himmelman et al. 2008). Thus hydrodynamic regime is likely to influence the relative importance of processes occurring in different locations around a spawning animal to overall fertilization.

Fertilization has also been viewed primarily as a short-term process where rates of mixing in the water column quickly reduce the probability of fertilization to very low levels after gamete release. However, gametes can be retained on the surface of an animal for long periods of time (Svane \& Havenhand 1993, Marshall 2002) and form clumps or strings that float in the water column, thus releasing eggs or sperm over time (Thomas 1994a). This retention can result in fertilizations occurring over a relatively long time frame (Yund \& Meidel 2003). The length of time over which these processes impact fertilization is influenced by hydrodynamic control on gamete retention and mixing within the water column. Thus fertilization not only occurs in multiple locations around a spawning animal but also over a changing time frame. The relative importance of different locations and the length of time fertilization occurs are modulated by the interaction of gamete properties and local hydrodynamic conditions.
Echinoids have been the principal model system for studying ecological questions about fertilization in broadcast-spawning animals. Many studies on this group have used containers of eggs to examine fertilization in the water column in the absence of a female (Pennington 1985, Levitan et al. 1992, Levitan \& Young 1995, Wahle \& Peckham 1999, Gaudette et al. 2006) or sampled eggs in the water column after release from a spawning animal (Franke et al. 2002, Levitan 2002, 2004, 2005, Levitan \& Ferrell 2006). Thus none of these studies attempted to examine the complex interactions among flow, morphology, hydrodynamics, and location-specific fertilization. To date, the study of the effects of flow on location-specific fertilization in echinoids has been limited to a comparison among the percentage of eggs fertilized in different locations under only 2 controlled flow conditions (Yund \& Meidel 2003). Also because the numbers of eggs fertilized in these locations was not quantified, we do not know how the relative importance of different locations to total fertilization (actual percentage of spawned eggs fertilized) varies with flow conditions.

Here we advance our understanding of fertilization in broadcast-spawning invertebrates by examining fertilization in the green sea urchin Strongylocentrotus droebachiensis. We quantified (1) fertilization over a broad range of flow velocities, (2) the effects of time on fertilization under different flow conditions, and (3) the relative contribution of different locations to total fertilization.

\section{METHODS AND MATERIALS}

\section{Assessing fertilization}

To assess effects of hydrodynamics, time, and location on fertilization in the green sea urchin, we conducted a series of experiments between 7 February and 7 March 2006 in a flow-through flume similar to that used by Yund \& Meidel (2003). The working section was a $3 \times 0.5 \mathrm{~m}$ rectangular box, filled to a depth of $0.2 \mathrm{~m}$. A condenser, collimator, and baffle in the entrance region were used to ensure a uniform distribution of flow in the working section of the flume. To provide a uniform rough surface, the floor of the flume was covered with Lego ${ }^{\mathrm{TM}}$ base plates $(0.25 \times$ $0.25 \mathrm{~m}$ ) glued to a $0.09 \mathrm{~m}$ thick acrylic sheet. Urchins were secured to this base at fixed positions at the center of the flume ( $y$-axis) so that the male and female urchins were located 1.8 and $2.8 \mathrm{~m}$, respectively, downstream from the entrance to the working section. 
Fertilization experiments were conducted at 4 mainstream flow velocities of $2,5,10$, and $15 \mathrm{~cm} \mathrm{~s}^{-1}$ (3 replicates per velocity). These mean velocities are within the range typically measured for tidal currents in protected sea urchin habitats of the Gulf of Maine (Gaudette et al. 2006, P. Yund \& F. Thomas unpubl. data: velocity at $10 \mathrm{~cm}$ above the bottom in the field; range $0.02-0.12$, mean $=0.06, \mathrm{SD}=0.03)$. Velocity data in the streamwise $(x)$, cross-stream $(y)$, and horizontal $(z)$ directions (velocities hereafter labeled $u, v$, and $w$, respectively) were recorded at $16 \mathrm{~Hz}$ for $5 \mathrm{~min}$ bursts every 30 min with an acoustic Doppler velocimeter (ADV; SonTek ADVField) during each experimental run. The ADV was positioned $12 \mathrm{~cm}$ above the substrate and $20 \mathrm{~cm}$ upstream of the female sea urchin. For each velocity, the flow characteristics within the flume were characterized from profiles taken across the flume and across depths to ensure that there was a developed boundary layer and that there were no significant secondary flows across the flume. During each fertilization trial, we calculated both mean velocity $(\bar{u})$ and a measure of turbulence (total kinetic energy, TKE $=0.5\left[u^{\prime 2}+v^{\prime 2}+\right.$ $w^{\prime 2}$ ], where $u^{\prime}, v^{\prime}, w^{\prime}$ are fluctuations in velocity; Denny 1988, Nikora et al. 1998). Data were filtered prior to calculations using established techniques (Nikora et al. 1998).

Urchins were collected from the northern coast of Maine (USA) and kept in flow-through tanks at ambient seawater temperatures $\left(1-4^{\circ} \mathrm{C}\right)$. Urchins used for experiments had mean \pm SE test diameters of $6.9 \pm$ $0.12 \mathrm{~cm}$ and were induced to spawn via 3.0 to $5.0 \mathrm{ml}$ injections of $0.5 \mathrm{M} \mathrm{KCl}$. Injection of $\mathrm{KCl}$ is a standard technique that produces gamete release similar to natural spawning events and has been used in numerous fertilization experiments (Pennington 1985, Levitan et al. 1992, Levitan \& Young 1995, Wahle \& Peckham 1999, Franke et al. 2002, Levitan 2002, 2004, 2005, Levitan \& Ferrell 2006). When spawning began, 1 male and 1 female were placed in the flume at one of the trial velocities. Piles of gametes on the aboral surface of spawning animals thus formed while urchins were in flowing water and not prior to the experiment.

The first sample of eggs was collected either 5 (for the 10 and $15 \mathrm{~cm} \mathrm{~s}^{-1}$ trials) or $10 \mathrm{~min}\left(2\right.$ and $\left.5 \mathrm{~cm} \mathrm{~s}^{-1}\right)$ after placing the urchins in the flume. To explore possible variation in fertilization with time, we sampled each trial at 4 to 6 different times. Sample times were evenly spaced throughout the period in which gametes were present on the spawning animals, but because the retention time of gametes on the surface of adults decreased with increasing velocity, sampling intervals and duration were inversely related to velocity. Sampling was terminated when either 6 samples had been collected or when eggs or sperm were no longer visible on the aboral surface (i.e. no further fertilization was possible).

At each time point, contemporaneous samples were collected at the following locations (Fig. 1): (1) top of the egg mass on the aboral surface; (2) substrate immediately downstream of the female; (3) wake, $5 \mathrm{~cm}$ downstream; (4) water column, $50 \mathrm{~cm}$ downstream of the female at a height approximately $10 \mathrm{~cm}$ above the substrate. The water column was sampled for $1 \mathrm{~min}$ with an open-ended $11.5 \mathrm{~cm}$ diameter cylinder with $35 \mu \mathrm{m}$ mesh walls and base. Sampling for 1 min may result in some fertilization occurring in the sampling process, which may overestimate the contribution of the water column to overall fertilization (i.e. bias our results against detecting non-water-column fertilization). However, fertilization envelopes (our assay of fertilization) also take $1 \mathrm{~min}$ to form, so any apparent inflation of water column fertilization should have been minimal. Samples were collected from the wake with a $50 \mathrm{ml}$ syringe with an extension tube. Eggs sampled from the water column and wake were rinsed with seawater (aged for 24-48 h to eliminate ambient sperm) into glass vials and fixed with a mixture of $2 \mathrm{ml} 37 \%$ formaldehyde and $10 \mathrm{ml}$ aged seawater within 1 min of collection. Eggs on the aboral surface and substrate were collected from the surface layer of their respective piles with a pipette and fixed in $5 \mathrm{ml}$ aged seawater and $1.5 \mathrm{ml} 37 \%$ formaldehyde within 1 min of collection.

The percentage of eggs fertilized (PF) for each sample was calculated from all eggs collected or from a random sample of 100 if $\geq 100$ eggs were collected; samples with $<10$ eggs were not included in the analysis. Eggs were considered fertilized if a fertilization membrane was present.

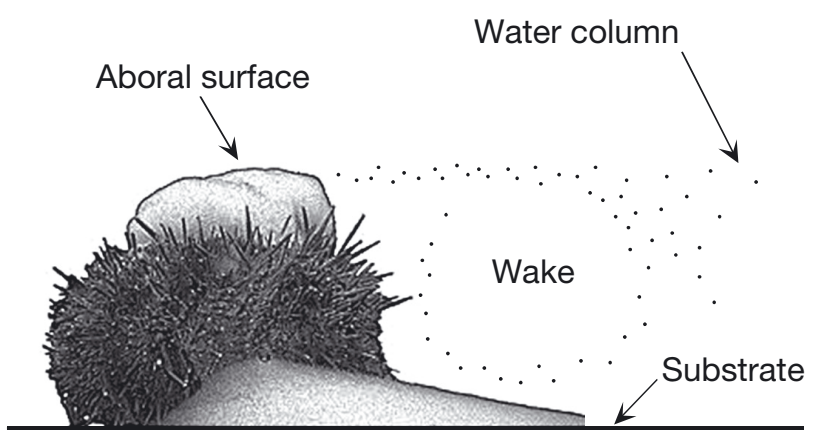

Fig. 1. Strongylocentrotus droebachiensis. Female with associated gamete piles and sample locations: aboral surface, substrate, wake, and the water column (sampled $50 \mathrm{~cm}$ downstream of the female and approximately $10 \mathrm{~cm}$ above the substrate). Drawing not to scale 
A control sample of eggs and sperm was assessed before the start of each experiment for: (1) the presence of fertilization envelopes (indicative of mechanical damage or sperm contamination), (2) the presence of immature eggs, (3) the ability of each male/ female pair to fertilize (sensu Palumbi 1999, Levitan \& Ferrell 2006; >95\% fertilization required to continue the trial). To test for background sperm in the seawater, 1 control trial with no male urchin was conducted at each mainstream velocity.

To check for an indication of polyspermy or false fertilization envelopes from physical damage, samples were collected from the water column, substrate, and aboral surface at the third time point, placed into aged seawater, refrigerated at $4^{\circ} \mathrm{C}$ for $8 \mathrm{~h}$, and then assayed for development. Eggs with fertilization envelopes that failed to cleave were considered to have either physical damage or developmental abnormalities, possibly due to polyspermy.

\section{Effect of hydrodynamics on fertilization}

The percentages of eggs fertilized at each location (Fig.1; water column, wake, substrate, aboral surface) were compared to $\bar{u}$ and TKE of the flow using regression of the arcsine-transformed values of the mean. Since TKE and $\bar{u}$ are highly correlated, we used the residuals of the regression of TKE versus $\bar{u}$ to test for any added levels of prediction offered by including TKE. Analysis of covariance (ANCOVA) was not used because samples were not independent (eggs from one location could transit to other locations).

The above calculation provides an overall estimate of the PF at each location under each set of hydrodynamic conditions, but does not give an indication of how many eggs were fertilized in each location. To determine the contribution of different locations to fertilization, we estimated the number of eggs that were in each location over the course of the experiment and calculated the proportion of fertilization attributable to each location. We excluded the wake location from the analysis because it was not possible to quantify the numbers of eggs transiting the wake.

\section{Determination of numbers of eggs in each location}

Piles of eggs formed on the substrate and on the aboral surface of the urchin under most flow conditions. Because we could not destructively sample these piles without interfering with fertilization during the experiments, we established a relationship between the number of eggs in the piles and the volume of the piles estimated from photographs in 6 preliminary trials for this purpose. We allowed 6 female urchins to spawn for $1 \mathrm{~h}$ at a very slow flow $\left(2 \mathrm{~cm} \mathrm{~s}^{-1}\right)$ and then collected and counted all of the eggs on the aboral surface and in piles that formed on the substrate at the base of the urchin. Due to the slow flow, there was little advection of eggs from the surface of the female or from the substrate piles. The average number of eggs spawned by a female urchin $\left(E_{\text {spawn }}\right)$ was $2.2 \times 10^{7}, \mathrm{SD}=4.5 \times 10^{5}$.

Volumes of the piles were estimated from photographs from the side and top using Image-Pro ${ }^{\circledR}$ Plus (Media Cybernetics, version 4.1 for Windows ${ }^{\mathrm{TM}}$ ), based on equations for the closest simple geometric shapes (i.e. cones and ellipses). We then regressed the number of eggs enumerated versus volume of piles estimated from photographs, yielding good approximations (Aboral $=13 \times 10^{4}$ eggs $\mathrm{ml}^{-1}$, $\mathrm{R}^{2}=0.92, \mathrm{n}=6$; Substrate $=5 \times 10^{4}$ eggs $\mathrm{ml}^{-1}$, $\mathrm{R}^{2}=0.88, \mathrm{n}=6$ ). Residuals from these regressions were randomly distributed, suggesting that no systematic error in estimating egg numbers occurred in larger- or smaller-volume piles. The differences in numbers of eggs per volume in the 2 locations is likely due to hydration of the egg jelly coat over time and the long retention time of eggs on the substrate at the flow speed used $\left(2 \mathrm{~cm} \mathrm{~s}^{-1}\right)$.

\section{Aboral}

All eggs spawned were assumed to transit the aboral surface; thus $E_{\text {aboral }}=E_{\text {spawn. }}$. At the end of some trials, a pile of eggs remained on the aboral surface $\left(E_{\text {left }}\right)$. The volumes of these piles were estimated from photographs via the regressions of enumerated eggs versus photo-estimated volume described above.

\section{Substrate}

We estimated the total number of eggs in substrate piles at each sampling period $\varepsilon(t)$, from photographs as described above. The number of eggs in the substrate pile results from 2 processes: eggs are added by falling from the aboral surface of the urchin into the pile and eggs are lost from the pile through resuspension or bedload transfer. To estimate the total number of eggs that pass through the piles during an entire fertilization trial ( $\left.E_{\text {substrate }}\right)$, we need to account for both processes. While eggs are still being released from the urchin (from $t=0$ to $t=t_{\text {max }}$ ), we assumed 
that eggs arrive into the substrate pile at an unknown but constant rate, $r_{\mathrm{p}}$ (eggs $\mathrm{min}^{-1}$ ); the total number of eggs that arrive in the pile is $r_{\mathrm{p}} t_{\text {max }}$. Eggs are lost from the pile as a constant proportion of pile size, $k \varepsilon(t)$, where $\varepsilon(t)$ is the number of eggs in the pile at time $t$. Therefore, during egg release, the dynamics of the pile can be described by the differential equation $\varepsilon=r_{\mathrm{p}}-k \mathrm{e}(t)$, which integrates to

$$
\varepsilon\left(t<t_{\max }\right)=\frac{r_{\mathrm{p}}}{k}\left(1-\mathrm{e}^{-k t}\right)
$$

Once eggs no longer arrive from the aboral surface (at $\left.t_{\max }\right)$, the egg pile simply declines exponentially:

$$
\varepsilon\left(t \geq t_{\max }\right)=\varepsilon(t) \mathrm{e}^{-k t}
$$

We determined $t_{\max }$ and $\varepsilon\left(t_{\max }\right)$ directly from the data: $\varepsilon\left(t_{\max }\right)$ is the maximum number of eggs measured and $t_{\max }$ is the time of that measurement. We estimated $k$ from the rate of exponential decline when $\left(t>t_{\max }\right)$ (Eq. 2). To estimate $r_{\mathrm{p}}$, we fit the data from $t \leq t_{\max }$ to Eq. (1) using the estimated value of $k$. We estimated the total number of eggs that remained or passed through the substrate pile as $E_{\text {substrate }}=r_{\mathrm{p}} t_{\text {max }}$.

\section{Water column}

Eggs that did not pass through the substrate pile or remain on the aboral surface were assumed to enter the water column directly from the aboral surface. While some eggs passing through the substrate piles may have been resuspended into the water column, observation suggested that most eggs were transported for some distance as bedload, and the minority that subsequently entered the water column did so well downstream of the site of water column sampling. Consequently, we assumed that all of the eggs from the substrate were transported as bedload and did not enter the water column (at least on the spatial scale of our experiment). Thus the total number of eggs entering the water column $\left(E_{\text {water }}\right)$ was calculated as the total number of eggs spawned minus the eggs transiting the substrate pile and those left on the aboral surface after the trial $\left(E_{\text {water }}=E_{\text {spawn }}-\right.$ $\left.E_{\text {substrate }}-E_{\text {left }}\right)$.

\section{Calculation of the percentage of total fertilization and relative contribution of location}

We combined our estimates of the number of eggs passing through each location and the PF at each location to estimate the number of eggs fertilized (NFT) at each location. Eggs on the aboral surface were simply assumed to be fertilized at the level measured during the experiments $\left(\mathrm{NFT}_{\mathrm{aboral}}=\mathrm{PF}_{\mathrm{aboral}}\right.$ $\left.\times E_{\text {spawn }}\right)$. In the substrate piles, some eggs arrive in the pile previously fertilized at the aboral surface and then additional fertilizations occur on the substrate $\left[\mathrm{NFT}_{\text {substrate }}=\left(\mathrm{PF}_{\text {aboral }}-\mathrm{PF}_{\text {substrate }}\right) \times E_{\text {substrate }}\right]$. Similarly in the water column, some eggs arrive fertilized from the aboral surface and others are fertilized in the water column $\left[\mathrm{NFT}_{\text {water }}=\left(\mathrm{PF}_{\mathrm{aboral}}-\mathrm{PF}_{\text {water }}\right) \times E_{\text {water }}\right]$. For each location, we calculated the mean and SE of the number of eggs that were fertilized for low $\left(<5 \mathrm{~cm} \mathrm{~s}^{-1}, \mathrm{n}=3\right.$ ), medium (5 to $<10 \mathrm{~cm} \mathrm{~s}^{-1}, \mathrm{n}=6$ ), and high ( $\geq 10 \mathrm{~cm} \mathrm{~s}^{-1}, \mathrm{n}=3$ ) velocity categories. Each mean includes the estimation error for each run and the SE simply represents the error among these means. From these we calculated the proportion of eggs fertilized $\left(\mathrm{PTF}=\mathrm{NTP}_{\text {location }} / E_{\text {spawn }}\right)$ at each location and estimated the relative contribution (RCO) of each location to overall fertilization occurring within each velocity category.

\section{Spawn viscosity}

For each of the 3 batches of urchins collected, we measured the viscosity of gametes from 3 males and 3 females with a cone and plate viscometer (Brookfield model DV-II) over a range of 8 shear rates ( 0.6 to $120 \mathrm{~s}^{-1}$ ) at a temperature of $0^{\circ} \mathrm{C}$. A power function of viscosity versus shear rate yields a proportionality constant $k$, where higher values of $k$ indicate a greater apparent viscosity for the fluids over all shear rates (see Thomas 1994a). An ANOVA (JMP 4.0.4; SAS Institute) was used to test differences in this apparent viscosity among gender and batch.

\section{RESULTS}

PF was low during the first time period for each location sampled (Fig. 2) at all 4 nominal velocities. After this initial sample, PF reached a maximal level and at lower velocities remained relatively constant throughout the experimental time period as long as gametes were present. At higher velocities, PF increased throughout the experiment in some locations (Fig. 2). This trend occurred at least in part because all eggs had been advected from the females before the period of maximum fertilization observed in slower flow experiments. Measurements at higher flows necessarily represent fertilization over shorter time frames than those at slower rates because eggs are transported out of the experimental area. 

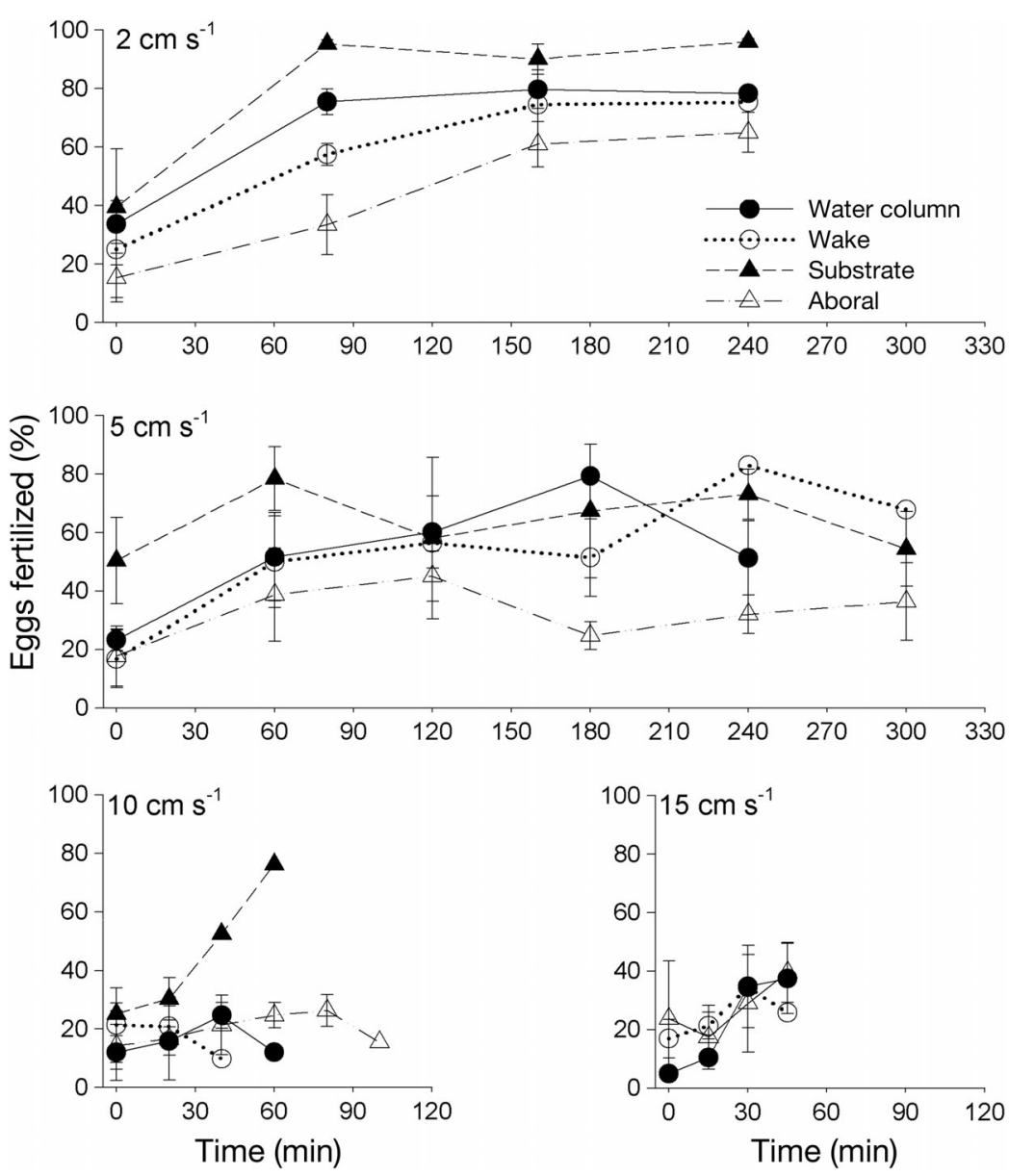

Fig. 2. Strongylocentrotus droebachiensis. Temporal patterns of percentage fertilization at velocities $(\bar{u})$ of $\sim 2,5,10$, and $15 \mathrm{~cm} \mathrm{~s}^{-1}$. Symbols represent the mean $\pm \mathrm{SE}(\mathrm{n}=2-3)$ percent of eggs fertilized at 4 sampling locations relative to the female: water column, wake, substrate, and aboral surface

Table 1. Regression analysis (arcsine transformed PF versus $\ln \bar{u}$ ) of percent fertilization of Strongylocentrotus droebachiensis eggs versus flow velocity (see Fig. 3) for eggs in 4 locations relative to the female (see Fig. 1)

\begin{tabular}{|lcccc|}
\hline Location & $\mathrm{R}^{2}$ & $F$ & $\mathrm{df}$ & $\mathrm{p}$ \\
\hline Aboral & 0.43 & 7.6 & 11 & 0.02 \\
Wake & 0.73 & 25.3 & 11 & 0.0005 \\
Substrate & 0.85 & 51.8 & 11 & $<0.0001$ \\
Water column & 0.66 & 16.3 & 11 & 0.002 \\
\hline
\end{tabular}

ity and making no contribution at the highest velocity category. The decline in importance of the substrate was due to both the decrease in the percentage of eggs fertilized at this location with flow (Fig. 3C) and the decrease in size of piles formed. Locations local to the female urchin (aboral and substrate) represented approximately $80 \%$ of the eggs that were fertilized across all of the velocity categories (Fig. 4B), with the contribution of the aboral surface to overall fertilization increasing with increasing velocity. Thus fertilization at locations close to the female made a large contribution to overall fertilization under the range of hydrodynamic conditions tested. Water column fertilization played a less important role than local fertilization overall, and its contribution to fertilization declined with increasing velocity.

PF was significantly dependent on $\bar{u}$, at all locations (Fig. 3, Table 1). Adding the effects of TKE on fertilization by regressing the residuals of $\bar{u}$ versus fertilization on TKE did not yield a significant regression (ANOVA, $\mathrm{df}=11, \mathrm{p}>0.4, \mathrm{R}^{2}<0.1$ ) for any position.

Controls to determine background sperm in the flume indicated that no sperm were present. Indicators of polyspermy and egg damage were minimal in all experiments. On average, $>90 \%$ of the fertilized eggs developed. There was no significant regression between percentage of the fertilized eggs that subsequently developed and $\bar{u}$, or location (ANOVA, $\mathrm{df}=2$, $F=0.45, \mathrm{p}>0.5$ ).

The percentage of total eggs spawned that were fertilized (PFT) in the water column, aboral surface, and substrate declined with increasing velocity (Fig. 4A). The relative importance of the different locations varied with velocity, with the substrate playing a substantial role in total fertilization at low veloc-
There were no significant effects of gender or batch of urchins in the apparent viscosity $(k)$ of gametes over the spawning season (ANOVA, $\mathrm{df}=2$, $F_{\text {batch }}=2.3, F_{\text {gender }}=3.3, p_{\text {batch }}>0.13, p_{\text {gender }}>0.09$ ). Although the differences were not significant, apparent viscosity of the gametes ranged from 2.7 to 3.9 Pa s among batches and tended to be higher for females (3.6 Pa s) than for males (2.7 Pa s). Variation in viscosity among individuals was higher than any systematic gender or batch effects.

\section{DISCUSSION}

Our results emphasize the importance of time, hydrodynamics, and location relative to the female on fertilization in the green sea urchin Strongylocentrotus droebachiensis. We found negative relationships between water velocity and both the percent- 


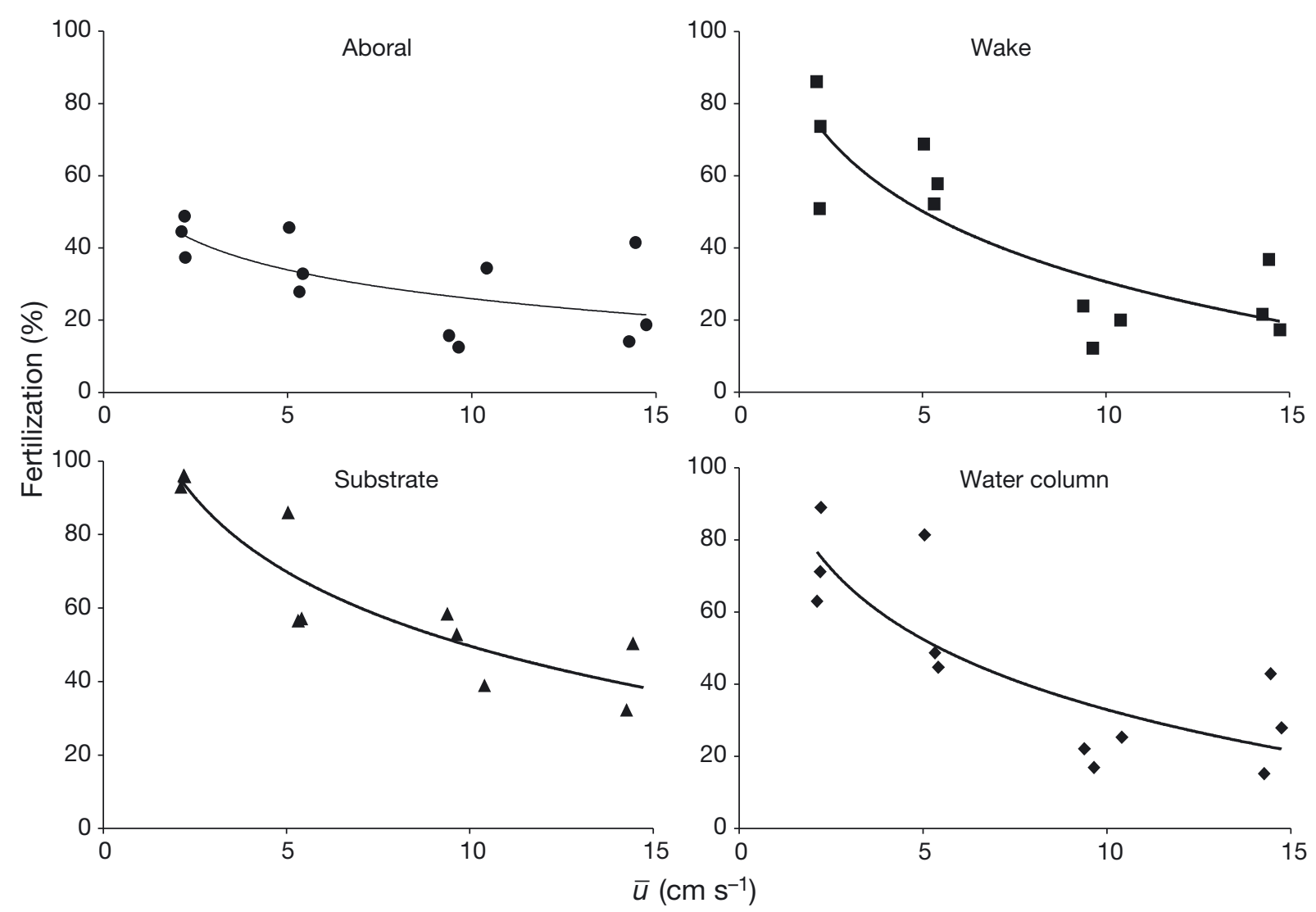

Fig. 3. Strongylocentrotus droebachiensis. Mean percent fertilization (PF) as a function of flow velocity $(\bar{u})$ at 4 sampling locations relative to the female. Symbols represent weighted means of the sample times. The 4 sampling locations are aboral surface, wake, substrate, and water column. All of the locations have a significant relationship to $\bar{u}_{\text {; }}$ statistics for arcsinetransformed PF versus $\ln \bar{u}$ are given in Table 1
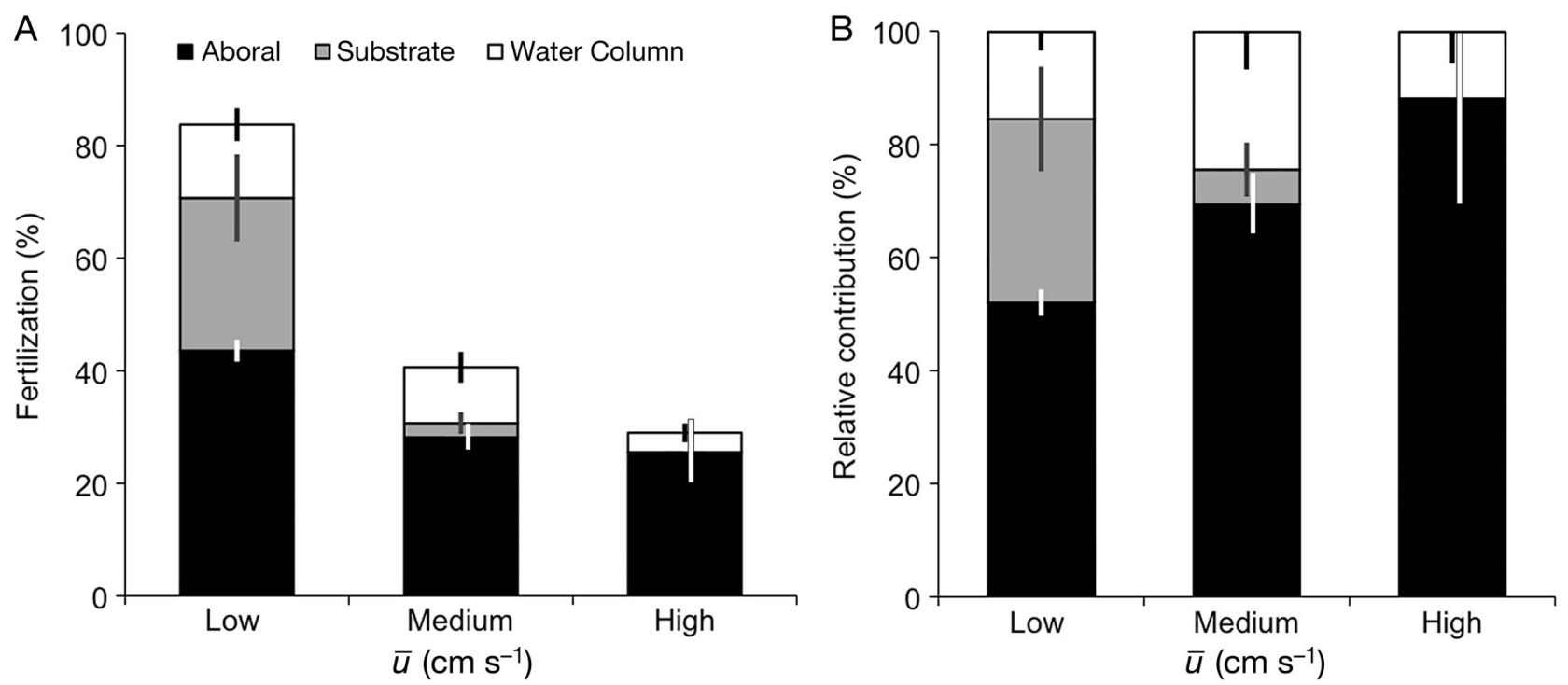

Fig. 4. Strongylocentrotus droebachiensis. Estimate of (A) the percentage of the total number of eggs spawned that were fertilized and (B) the relative contribution to overall fertilization at the aboral surface, the substrate, and in the water column as a function of velocity $(\bar{u})$ categories: low $\left(<5 \mathrm{~cm} \mathrm{~s}^{-1}\right)$, medium $\left(5\right.$ to $\left.<10 \mathrm{~cm} \mathrm{~s}^{-1}\right)$, and high $\left(>10 \mathrm{~cm} \mathrm{~s}^{-1}\right)$. Error bars: SEM. Note that local fertilization plays an important role in fertilization at all velocities 
age of eggs fertilized (Fig. 3) and the proportion of eggs that were fertilized (Fig. 4A) at each location. Hydrodynamics also influenced the relative importance of different locations to overall fertilization (Fig. 4B). At all flows, local fertilization (aboral surface + substrate) contributed a major portion of the total portion of eggs fertilized, and the relative contribution of the aboral surface to overall fertilization increased at higher flows. This is an important result, as it implies that eggs are fertilized as they are released from a female so processes that control egg and sperm mixing at this location could be far more important than previously thought.

Flow conditions played a major role in fertilization in these broadcast-spawning animals, and more fertilization occurred near the female than in the water column. However, our simple experiments pairing 1 female and 1 male within close proximity could under-estimate the importance of water column fertilization if eggs continue to encounter sperm plumes from other males as they are advected downstream. This scenario might occur in a widely distributed, synchronized natural spawning event (Himmelman et al. 2008).

The interactions of small-scale hydrodynamic conditions, urchin morphology, and spawn viscosity contribute to the retention of gametes on the aboral surface. In females, retention enables fertilization at this location, while in males, it results in the formation of sperm clumps and strings (Thomas 1994a) that contribute to sperm longevity and thus the long time course of fertilization (Meidel \& Yund 2001,Yund \& Meidel 2003). The spawn of Strongylocentrotus droebachiensis is retained because of its high viscosity. Female spawn was within the range of those reported for other urchins (3.6 to 6.8 Pa s, Thomas 1994a), while viscosity values for sperm were higher compared to other species surveyed ( $k=1.5$ Pa s, Thomas 1994a).

In our experiments, fertilization occurred over a longer time frame than is usually considered in empirical examinations of fertilization efficiency in broadcast-spawning animals. At low velocities, fertilization continued for hours (Fig. 2A,B) as sperm were slowly released from clumps and strings of sperm that formed on the male's aboral surface and interacted with eggs retained on the female. Even at the highest flows, fertilization continued for close to $1 \mathrm{~h}$ (Fig. 2D). In all experiments, PF was lowest in the first time frame (Fig. 2); then, depending on the nominal velocity, it either increased to a plateau level or continued to increase throughout the experiment because eggs left the experimental field before maximum fertilization was reached.
Most past research (but see Meidel \& Yund 2001, Yund \& Meidel 2003) on urchin fertilization in the laboratory and field limited sampling to the first few minutes after spawning was initiated or gametes were released. To date, we do not know what controls the time lag we and other researchers (Yund \& Meidel 2003) have seen in fertilization; however, this lag presents a very interesting question: If rapid dilution of gametes is a major factor limiting fertilization for broadcast-spawning invertebrates, why is there a time lag between spawning and maximum fertilization levels?

Across all velocities, $>90 \%$ of all fertilized eggs subsequently developed, thus mechanical damage (which can cause false fertilization envelopes, i.e. fertilization envelopes that rise even though eggs are not fertilized) and polyspermy were relatively low. We attempted to directly assay polyspermy, but eggs in our samples were routinely fertilized many minutes prior to collection, thus the sperm pronuclei had already decondensed at the time of sampling and could not be visualized with nuclear stains (Author's unpubl. data; see Franke et al. 2002 for more on this approach). Consequently, we can only infer maximum polyspermy levels from the reduction in development in live samples relative to pickled samples and conclude that when sea urchins are separated by $1 \mathrm{~m}$, polyspermy will occur for $<10 \%$ of the eggs across a range of flow conditions and fertilization locations.

These experiments were conducted in a unidirectional flume, and we recognize the limitation of these hydrodynamic conditions and the placement of the female directly downstream of a spawning male. However, the mainstream flows we used are likely to be relevant to urchin habitats in the Gulf of Maine. It is currently difficult to quantify hydrodynamic conditions in natural Strongylocentrotus droebachiensis habitats because populations have been greatly impacted by commercial harvesting, which has shifted the community structure from sea urchin barrens to macroalgae (see Steneck et al. 2004 and references therein), thus altering flow regimes. However, available evidence indicates that a large portion of the population lives below $8 \mathrm{~m}$ depth (Whitman \& Dayton 2001), and mean velocities measured in the Gulf of Maine on protected coastlines at comparable depths are generally $<0.10 \mathrm{~m} \mathrm{~s}^{-1}$ (Gaudette et al. 2006, P. Yund \& F. Thomas unpubl. data).

Fertilization in the water column may represent only a portion of total fertilizations, and the processes that control fertilization at other locations may play a major role in the efficiency of fertilization in many 
broadcast spawners. It is probable that broadcast spawning occurs over a continuum. At one extreme, all fertilization may take place in the water column (slow steady flow), while at the other extreme, all fertilization takes place at the female's surface as eggs are released (high unsteady flow). Between these extremes, fertilization takes place at multiple locations in the vicinity of spawning animals. The relative importance of these locations will differ among taxa and be mediated by local hydrodynamics, gamete properties, and animal morphology. It is probable that wave action plays a role in determining the relative importance of local fertilization, thus the continuum from water column to local fertilization could be distributed along a wave gradient such as shallow to deep sites.

To date, a body of literature has developed that explores processes controlling water column fertilization over relatively short time scales (e.g. Pennington 1985, Denny 1988, Levitan 1991, Babcock et al. 1992, Levitan et al. 1992, Coma \& Lasker 1997, Wahle \& Peckham 1999, Crimaldi \& Browning 2004, Gaylord 2008). Considering our results, it seems clear that a broader approach that includes realistic flow regimes (Jumars et al. 2001), consideration of animal morphology and gamete properties (Thomas 1994a,b, Marshall et al. 2004), along with time-integrated analysis of fertilization (e.g. Williams \& Bentley 2002, Yund \& Meidel 2003, Gaudette et al. 2006, Lasker 2006 ) is required to fully understand the efficiency of fertilization in broadcast spawners.

Acknowledgements. We thank E. Zimmermann, S. Stickley, R. Grabowski, and J. Zima for assistance in the laboratory. Funding was provided by the National Science Foundation (OCE-04-25088 and OCE-12-33868 to P.O.Y. and OCE-0424978 to F.I.M.T.). This is contribution number 1570 from the Hawaii Institute of Marine Biology and 9018 from The University of Hawaii- SOEST.

\section{LITERATURE CITED}

Babcock R, Mundy C, Keesing J, Oliver J (1992) Predictable and unpredictable spawning events: in situ behavioural data from free-spawning coral reef invertebrates. Invertebr Reprod Dev 22:213-228

- Coma R, Lasker HR (1997) Effects of spatial distribution and reproductive biology on in situ fertilization rates of a broadcast-spawning invertebrate. Biol Bull (Woods Hole) 193:20-29

> Crimaldi JP (2012) The role of structured stirring and mixing on gamete dispersal and aggregation in broadcast spawning. J Exp Biol 215:1031-1039

Crimaldi JP, Browning HS (2004) A proposed mechanism for turbulent enhancement of broadcast spawning efficiency. J Mar Syst 49:3-18
Denny MW (1988) The biology and mechanics of the wave swept environment. Princeton University Press, Princeton, NJ

> Denny M, Dairiki J, Distefano S (1992) Biological consequences of topography on wave-swept rocky shores: I. Enhancement of external fertilization. Biol Bull (Woods Hole) 183:220-232

> Denny MW, Nelson EK, Mead KS (2002) Revised estimates of the effects of turbulence on fertilization in the purple sea urchin, Strongylocentrotus purpuratus. Biol Bull (Woods Hole) 203:275-277

> Franke ES, Babcock RC, Styan CA (2002) Sexual conflict and polyspermy under sperm-limited conditions: in situ evidence from field simulations with the free spawning marine echinoid Evechinus chloroticus. Am Nat 160: 485-496

Fredsoe J, Deigaard R (1992) Mechanics of coastal sediment transport. World Scientific Publishing, Singapore

- Gaudette J, Wahle RA, Himmelman JH (2006) Spawning events in small and large populations of the green sea urchin Strongylocentrotus droebachiensis as recorded using fertilization assays. Limnol Oceanogr 51: 1485-1496

Gaylord B (2008) Hydrodynamic context for considering turbulence impacts on external fertilization. Biol Bull (Woods Hole) 214:315-318

Gyr A, Kinzelbach W (2003) Sedimentation and sediment transport. Kluwer Academic Publishing, Dordrecht

Himmelman JH, Dumont CP, Gaymer CF, Vallières C, Drolet D (2008) Spawning synchrony and aggregative behaviour of cold-water echinoderms during multi-species mass spawnings. Mar Ecol Prog Ser 361:161-168

Jumars PA, Eckman JE, Koch E (2001) Animals and plants in benthic flows. In: Boudreau B, Jørgensen BB (eds) The benthic boundary layer: transport processes and biogeochemistry. Oxford University Press, New York, NY, p 320-347

> Lasker HR (2006) High fertilization success in a surfacebrooding Caribbean gorgonian. Biol Bull (Woods Hole) 210:10-17

Levitan DR (1991) Influence of body size and population density on fertilization success and reproductive output in a free-spawning invertebrate. Biol Bull (Woods Hole) 181:261-268

Levitan DR (2002) The relationship between conspecific fertilization success and reproductive isolation among three congeneric sea urchins. Evolution 56:1599-1609

Levitan DR (2004) Density-dependent sexual selection in external fertilizers: variances in male and female fertilization success along the continuum from sperm limitation to sexual conflict in the sea urchin Strongylocentrotus franciscanus. Am Nat 164:298-309

Levitan DR (2005) Sex-specific spawning behavior and its consequences in an external fertilizer. Am Nat 165: 682-694

> Levitan DR (2008) Gamete traits influence the variance in reproductive success, the intensity of sexual selection, and the outcome of sexual conflict among congeneric sea urchins. Evolution 62:1305-1316

> Levitan DR, Ferrell DL (2006) Selection on gamete recognition proteins depends on sex, density and genotype frequency. Science 312:267-269

> Levitan DR, Young CM (1995) Reproductive success in large populations: empirical measures and theoretical predictions of fertilization in the sea biscuit Clypeaster rosa- 
ceus. J Exp Mar Biol Ecol 190:221-241

Levitan DR, Sewell MA, Chia F (1992) How distribution and abundance influences fertilization success in the sea urchin Strongylocentrotus franciscanus. Ecology 73: 248-254

Marshall DJ (2002) In situ measures of spawning synchrony and fertilization success in an intertidal, free-spawning invertebrate. Mar Ecol Prog Ser 236:113-119

Marshall DJ, Semmens D, Cook C (2004) Consequences of spawning at low tide: limited gamete dispersal for a rockpool anemone. Mar Ecol Prog Ser 266:135-142

Mead KS, Denny MW (1995) The effects of hydrodynamic shear stress on fertilization and early development in the purple sea urchin, Strongylocentrotus purpuratus. Biol Bull (Woods Hole) 188:46-56

Meidel SK, Yund PO (2001) Egg longevity and time-integrated fertilization in a temperate sea urchin (Strongylocentrotus droebachiensis). Biol Bull (Woods Hole) 201: 84-94

> Nikora VI, Suren AM, Brown SLR, Biggs BJF (1998) The effects of the moss Fissidens rigidulus (Fissidentaceae: Musci) on near-bed flow structure in an experimental cobble bed flume. Limnol Oceanogr 43:1321-1331

Palumbi SR (1999) All males are not created equal: fertility differences depend on gamete recognition polymorphisms in sea urchins. Proc Natl Acad Sci USA 96:12632-12637

Pennington JT (1985) The ecology of fertilization of echinoid

Editorial responsibility: Steven Morgan,

Bodega Bay, California, USA eggs: the consequences of sperm dilution, adult aggregation, and synchronous spawning. Biol Bull (Woods Hole) 169:417-430

Steneck RS, Vavrinec J, Leland AV (2004) Accelerating trophic-level dysfunction in kelp forest ecosystems of the Western North Atlantic. Ecosystems 7:323-332

Svane I, Havenhand JN (1993) Spawning and dispersal in Ciona intestinalis (L). PSZN I: Mar Ecol 14:53-66

Thomas FIM (1994a) Physical properties of gametes in three sea urchin species. J Exp Biol 194:263-284

Thomas FIM (1994b) Transport and mixing of gametes in three free-spawning polychaete annelids, Phragmatopoma californica (Fewkes), Sabellaria cementarium (Moore), and Schizobranchia insignis (Bush). J Exp Mar Biol Ecol 179:11-27

Wahle RA, Peckham SH (1999) Density-related reproductive trade-offs in the green sea urchin, Strongylocentrotus droebachiensis. Mar Biol 134:127-137

Williams ME, Bentley MG (2002) Fertilization success in marine invertebrates: the influence of gamete age. Biol Bull (Woods Hole) 202:34-42

Witman JD, Dayton PK (2001) Rocky subtidal communities, In: Bertness M, Gaines SD, Hay ME (eds) Marine community ecology. Sinauer, Sunderland, MA, p 339-366

Yund PO, Meidel SK (2003) Sea urchin spawning in benthic boundary layers: are eggs fertilized before advecting away from females? Limnol Oceanogr 48:795-801

Submitted: November 20, 2012; Accepted: October 13, 2013 Proofs received from author(s): November 12, 2013 